This item was submitted to Loughborough's Research Repository by the author.

Items in Figshare are protected by copyright, with all rights reserved, unless otherwise indicated.

\title{
The development of an mHealth educational intervention for first-time hearing aid users: combining theoretical and ecologically valid approaches
}

PLEASE CITE THE PUBLISHED VERSION

https://doi.org/10.1080/14992027.2020.1755063

\section{PUBLISHER}

Taylor \& Francis

\section{VERSION}

AM (Accepted Manuscript)

\section{PUBLISHER STATEMENT}

This is an Accepted Manuscript of an article published by Taylor \& Francis in International Journal of Audiology on 27 April 2020, available online: http://www.tandfonline.com/10.1080/14992027.2020.1755063.

\section{LICENCE}

CC BY-NC-ND 4.0

\section{REPOSITORY RECORD}

Maidment, David, Neil Coulson, Heather Wharrad, Mike Taylor, and Melanie Ferguson. 2020. "The Development of an Mhealth Educational Intervention for First-time Hearing Aid Users: Combining Theoretical and Ecologically Valid Approaches". Loughborough University. https://hdl.handle.net/2134/12097743.v1. 
The development of an mHealth educational intervention for first-time hearing aid users: combining theoretical and ecologically valid approaches.

David W. Maidment ${ }^{1,2,3}$, Neil S. Coulson ${ }^{4}$, Heather Wharrad ${ }^{5}$, Mike Taylor ${ }^{5}$, Melanie A. Ferguson $^{2,6,7}$

${ }^{1}$ School of Sport, Exercise and Health Sciences, Loughborough University, Loughborough, UK

${ }^{2}$ National Institute for Health Research (NIHR) Nottingham Biomedical Research Centre, Nottingham, UK

${ }^{3}$ Hearing Sciences Section, Division of Clinical Neuroscience, School of Medicine, University of Nottingham, Nottingham, UK

${ }^{4}$ Division of Rehabilitation, Ageing and Wellbeing, School of Medicine, University of Nottingham, Nottingham, UK

${ }^{5}$ School of Health Sciences, University of Nottingham, Nottingham, UK

${ }^{6}$ Nottingham University Hospitals NHS Trust, Queens Medical Centre, Nottingham, UK

${ }^{7}$ National Acoustic Laboratories, Sydney, Australia

\section{Corresponding author}

David Maidment, $\mathrm{PhD}$

School of Sport, Exercise and Health Sciences, Loughborough University, Epinal Way, Loughborough,

LE11 3TU

E.d.w.maidment@lboro.ac.uk

T. +44(0) 1509225439

\section{Running head}

Development of an mHealth intervention 


\section{ABSTRACT}

Objective. This paper describes the development of a novel mobile health (mHealth) educational intervention designed for first-time hearing aid users based on previously developed educational multimedia videos, or reusable learning objects (RLOs), branded C2Hear.

Design. The development of m2Hear used theoretical and ecologically valid approaches. The COM-B model and associated Theoretical Domains Framework were employed to identify specific components (or "active ingredients") of the original RLOs that facilitate hearing aid use. An mHealth platform was then developed following an iterative, user-centred and participatory design approach.

Study sample. Fifteen existing hearing aid users completed synchronous, real-time Think Aloud interviews. A sub-group of these participants $(n=5)$, along with patient and public involvement panel members $(n=4)$, subsequently reviewed the usability of the mHealth platform.

Results. While factors associated with Capability featured strongly across all RLOs, topics relating to Opportunity and Motivation were also incorporated. The RLOs were broken-down into 42 shorter mobile-enhanced RLOs (or mRLOs). Each mRLO was labelled with a specific user-centred question generated from the Think Aloud interviews. The final mHealth platform was developed following four separate usability iterations.

Conclusions. Overall, m2Hear provides greater opportunities for individualised learning and encourages greater interaction to facilitate self-management in first-time hearing aid users. 
Development of an mHealth intervention

\section{Key words}

Hearing Loss; Educational mHealth intervention; First-time hearing aid users; COM-B model; Theoretical Domains Framework; Think Aloud interview; Participatory design approach. 


\section{INTRODUCTION}

Individuals living with chronic conditions, such as hearing loss, are primarily responsible for managing their own health. Patient education is one of the core tenets of hearing loss selfmanagement (Barker et al., 2016b), supporting the individual to use, handle, maintain and care for their hearing aids on an ongoing basis (Bennett et al., 2018). Information to support hearing aid management is typically delivered verbally by an audiologist. However, hearing aid users often forget or misunderstand important information given to them in this way (Reese \& Smith, 2006; Ferguson et al., 2015). Audiologists can also experience difficulties disseminating the large amounts of information that patients require during time-limited appointments (Bennett et al., 2018). These factors likely contribute to the finding that, despite improving quality of life and listening abilities, hearing aids are often used sub-optimally or not at all (Ferguson et al., 2017).

High-quality information, which supplements that given verbally by an audiologist, can resolve some of the issues surrounding suboptimal and non-use of hearing aids. In the UK, for instance, the provision of accessible patient information is strongly advocated in national quality standards and practice guidance for adult aural rehabilitation (British Society of Audiology, 2016; National Institute for Health and Care Excellence, 2018). Supplementary information typically takes the form of written materials, such as hearing aid user guides and/or manuals. Research in this area has consequently investigated whether these materials are set at an appropriate level for the intended target audience to understand (i.e. health literacy). In general, the majority of hearing aid user guides have been deemed unsuitable for the typical first-time hearing aid user age group (i.e. older adults $>65$ years), which may also help to explain why hearing aids are used sub-optimally (Caposecco et al., 2014). Improving 
the content, layout and readability of written materials, such as through the inclusion of pictures or graphics, increasing the font size, as well as reducing reading level, can improve hearing aid outcomes (Caposecco et al., 2016; McMullan et al., 2018).

In addition to issues surrounding health literacy, a further complication is that written information is not always given to patients as standard (Kochkin et al., 2010). Remotely delivered educational interventions provides an accessible alternative to written materials. Such interventions include videos (Kramer et al., 2005) and internet-based programmes (Thorén et al., 2014), which have been shown to result in positive outcomes relative to standard care. Similarly, we have developed an educational intervention based on the concept of reusable learning objects (RLOs) (Ferguson et al., 2016a; Ferguson et al., 2018). RLOs are bite-sized chunks of multimedia learning underpinned by pedagogical design principles. Specifically, an appropriate multimedia environment is created whereby the learner focuses on specific learning goals. The learner is further encouraged to take an active role within the RLO, through a combination of highly visual components (e.g. animations, video clips patient testimonials), activities and self-assessments that are aligned with these goals.

To improve accessibility, we employed a user-centred and participatory design approach to develop a series of RLOs covering practical (e.g. How to insert hearing aids) and psychosocial (e.g. Communication tactics) aspects of the adult aural rehabilitation process (Ferguson et al., 2018). The effectiveness of the RLO intervention was assessed in a registered randomised controlled trial (RCT) (https://www.isrctn.com, ISRCTN11486888) of 203 first-time hearing aid users (Ferguson et al., 2016a). In comparison to a standard care control group, participants using the RLOs demonstrated significantly better practical hearing aid handling skills, better practical and psychosocial knowledge, and greater hearing aid use 
in suboptimal users. In a further clinically registered RCT (https://clinicaltrials.gov, NCT03912779), the RLOs were also shown to significantly improve self-efficacy for hearing aids (Gomez \& Ferguson, 2019). On completion of the first trial, the RLOs were further revised based on participant feedback and subsequently branded C2Hear. These RLOs are now freely available online via YouTube (https://www.youtube.com/c2hearonline), as well as a dedicated website (https://c2hearonline.com). However, the RLOs were originally developed for a DVD-mode of delivery. At the time of development (2011/12), internet use in the typical first-time hearing aid user age group (70-74 years) was only 17\% (Henshaw et al., 2012), suggesting that a DVD format would be most accessible to the target population. Consequently, opportunities for individualisation and interactivity were limited. Although participants in the original RCT could select the specific RLOs that they wanted to view, the average length of the videos was approximately eight-minutes. Some participants commented at the end of the trial that the RLOs were too long and hindered locating desired information with ease (Ferguson et al., 2016a). In addition, multiple-choice quizzes were included at the end of each RLO, which enabled participants to self-assess their mastery of the content and reinforce the intended learning goals. However, there were no opportunities to actively engage with the RLO content during learning to facilitate deeper understanding (Windle et al., 2011).

Providing healthcare via mobile technologies (e.g. smartphones, tablets, wearables), known as mobile health (or mHealth), is expanding rapidly as an accessible method of service delivery. In other chronic healthcare domains, such as diabetes, cardiovascular disease and asthma, mHealth interventions have been shown to increase individualisation and interactivity, improving self-management (Wang et al., 2014; Kim \& Lee, 2017). In addition, increasing individualisation and interactivity has been shown to enhance learning through 
active engagement with educational materials (Zhang et al., 2006; Evans \& Gibbons, 2007; Windle et al., 2011). The increasing digital literacy of older adults in the typical first-time hearing aid user age group suggests that mHealth interventions are likely an accessible and engaging method of providing educational support in this clinical population. In the UK, for example, smartphone ownership in people over the age of 55-years has increased exponentially, from 40\% in 2013 to $80 \%$ in 2019 (Deloitte UK, 2019). The proportion of 5564 year olds accessing the internet remotely via smartphones has also steadily increased, from 29\% in 2012 to 64\% in 2017 (Office for National Statistics, 2017).

In this paper, we describe the development process of an mHealth educational intervention for first-time hearing aid users based on our original RLO-based educational intervention. In accordance with the UK Medical Research Council's (MRC) guidelines (Medical Research Council, 2006), the development of the intervention was underpinned by appropriate theory. The original RLOs were developed using a participatory design approach and were underpinned by pedagogical design principles (Ferguson et al., 2018). However, since their development, there have been advances in the science of behaviour change theory, which presents a novel opportunity to retrospectively assess the theoretical basis of the RLOs. Specifically, we used the COM-B model (Michie et al., 2011), a contemporary, supra-theory of behaviour change that can enable intervention developers to better understand and describe patient behaviour (Coulson et al., 2016). The utility of this model is also being increasingly recognised and applied in range of audiological contexts (Barker et al., 2016a; Maidment et al., 2019). The model stipulates that for individuals to engage in a target Behaviour (B), they must have Capability (C), Opportunity (O), and Motivation (M). The COM-B model can also be incorporated into a larger system that includes the Theoretical Domains Framework (TDF). The TDF consists of 14 different constructs (Supplemental Materials 1) that can 
inform the identification of essential components, or "active ingredients", which can be incorporated in an intervention to bring about desired behaviour change.

The main objective of this paper is to describe how we developed an mHealth educational intervention (m2Hear) for first-time hearing aid users using both theoretical and ecologically valid approaches. Specifically, this study aimed to:

i. identify the "active ingredients" of the original C2Hear RLOs that facilitate the intended target behaviour (i.e. hearing aid use), theoretically grounded using the COM-B model and TDF; and

ii. develop an mHealth platform that meets the needs of the end-user following an iterative, user-centred and participatory design approach for delivering individualised learning and increased interactivity.

\section{METHODS}

\section{Theoretical approach}

\section{Identification of the C2Hear RLO "active ingredients"}

The extent to which each of the 14 factors from the TDF were included within each C2Hear RLO was first identified by four independent researchers. One researcher (DWM) assessed all RLOs, with the remaining co-authors each evaluating a randomly assigned subset of six RLOs. A purpose-designed coding sheet was used to record the start and finish times within each RLO corresponding to the appropriate TDF factor. An example of a completed coding sheet for one RLO (How to insert your hearing aids) is provided in Figure 1. 
To ensure coding consistency, two RLOs (How to insert your hearing aids; What to expect when wearing hearing aids) were initially assessed independently by all four authors. This was then followed by a calibration meeting, whereby any discrepancies between assigned timings were discussed. An agreement was subsequently made amongst authors regarding which timings should be applied for each TDF factor. Following this meeting, the TDF factors for the remaining RLOs were mapped independently. Authors agreed that where a minimum of two researchers provided sufficiently similar timings ( $<5$-seconds difference), no further action would be required. A final decision on further discrepancies was decided upon by MAF due to her audiological expertise.

The final agreed timings were used to calculate the percentage of time each the 14 factors from the TDF were included within each C2Hear RLO. For example, the total duration of the How to insert your hearing aids RLO was four-minutes, with consensus amongst authors resulting in one-minute and 51-seconds $(46.25 \%)$ being coded as knowledge; one-minute and 34-seconds (39.17\%) as physical skills; 12 -seconds (5\%) as memory, attention and decision processes; 48-seconds (20\%) as behaviour regulation; 26 -seconds (10.83\%) as social influences; 27 -seconds (11.25\%) as environmental context; one-minute and 18-seconds $(32.5 \%)$ as reinforcement; and 13 -seconds (5.42\%) as optimism.

\section{Ecologically valid approach}

\section{Generating the mobile-enhanced RLOs (mRLOs)}

The C2Hear RLOs were segmented into shorter mRLOs for delivery via mobile technologies, which was undertaken by two independent researchers. One researcher (DWM) segmented all the RLOs, with the remaining authors each segmenting a different, randomly assigned subset 
of four RLOs. The aim of this process was to break-down the C2Hear RLOs into mRLOs that were not only shorter in duration (approximately one-minute) but were also meaningful chunks of information that included a specific learning goal. Researchers recorded the start and finish times within each RLO that corresponded to an mRLO segment in accordance with these pre-specified criteria. On completion, all authors met to develop a consensus regarding which segment timings should be applied for each mRLO. Any differences between timings were discussed, and an agreement amongst all authors was made regarding which timings should be applied.

\section{Labelling the mRLOs}

We considered it important for the end user's voice to be embedded within the final mHealth intervention to improve learning potential. Consequently, a convenience sampling strategy was used (Patton, 1990), whereby 15 existing hearing aid users were recruited from the National Institute for Health Research (NIHR) Nottingham Biomedical Research Centre (BRC) participant database. Demographic information of the sample is provided in Table 1.

Participants were invited to attend the NIHR Nottingham BRC, where written informed consent was obtained. A synchronous, real-time Think Aloud interview was then completed. The Think Aloud technique is an established observational method (Fonteyn et al., 1993) that has been widely used in health research to evaluate digital interventions (e.g. Todhunter, 2015). In this study, individual participants viewed the mRLOs and were required to reflect upon, describe and summarise the content in their own words. At the start of the session, a trained researcher (DWM) initially demonstrated what was expected, using the C2Hear Introduction video (https://youtu.be/gZL8DUUKSKg) as an example. Participants were then provided an opportunity to ask any further questions before the Think Aloud interview began. 
All interviews were conducted face-to-face, in a quiet room and lasted approximately onehour in duration. Each interview was audio-recorded and transcribed verbatim.

The Think Aloud interview data were analysed by DWM using Braun and Clarke's (2006) established thematic analysis procedure, which comprises specific analytical phases: data familiarization, generating initial codes, searching for themes, reviewing themes, and defining and naming themes. The analysis was inductive, as no pre-existing coding frame (or theoretical framework) was employed, and themes were defined as something important about the data that represented repeated patterns of response or meaning that were prevalent (i.e. reported by several participants) across the entire data set (Braun \& Clarke, 2006). A second researcher (MAF) reviewed the codes generated from all transcripts. Labels (i.e. themes) were derived for each mRLO, which were defined and redefined through re-analysis of the data and discussions amongst DWM and MAF. The final labels were affirmed by a project-specific patient and public involvement (PPI) panel, consisting of four individuals with lived experience of hearing loss.

\section{Developing the mHealth delivery platform}

On completion of the Think Aloud evaluation, the mHealth intervention was developed by the Health and e-Learning Media (HELM) team at the University of Nottingham. The platform aimed to incorporate greater opportunities for individualisation and interactivity. Employing a user-centred and participatory design approach, a sub-group of participants were invited from the Think Aloud study ( $n=5)$, along with PPI panel members $(n=4)$, who reviewed the usability of the mHealth platform. This process was iterative, whereby individual participants interacted with prototype-versions of the intervention in the presence of one researcher (DWM) at the NIHR Nottingham BRC, as well as remotely from home, for 
up to one-week. During each iteration session, user perceptions and potential problems with the prototype versions of the platform were identified and collated. Feedback was then sent to the HELM team so that revisions could be made to the platform before the next iteration commenced. In total, four separate iterations were undertaken between November 2017 and February 2018, each taking approximately one-month to complete. This model of usability testing was an adaptation of the well-established methodology devised by the HELM team (Wharrad \& Windle, 2010), and was successfully used in the development of the original C2Hear RLOs (Ferguson et al., 2016a).

All participants were paid a nominal inconvenience allowance and travel expenses for taking part in the research. The study was approved by the National Health Service (NHS) Health Research Authority, East of England - Cambridgeshire and Hertfordshire Research Ethics Committee and Nottingham University Hospitals NHS Trust Research and Innovation department.

\section{RESULTS}

\section{Theoretical approach}

\section{Identification of the C2Hear RLO "active ingredients"}

The percentage of time each TDF factor was included within each C2Hear RLO is summarised in Figure 2. On average, all RLOs included a high proportion of time relating to domains associated with the Capability component of the COM-B model $(M=35.1 \%$; $S D=$ 13.7). The proportion of time associated with Opportunity $(M=19.8 \% ; S D=013.7)$ and Motivation $(M=5.8 \% ; S D=4.6)$ was lower. Arguably, these results were to be expected 
given that the original C2Hear RLOs all aimed to improve knowledge of hearing aids and communication.

This pattern of findings was also reflected in Figure 3, which shows the proportion of time each TDF factor was included within each individual RLO. The Hearing aid care RLO included TDF factors associated exclusively with Capability, with the highest proportion of time identified for Behavioural regulation (94.9\%). The remaining RLOs included TDF factors n related to Capability, as well as Opportunity and Motivation. A higher proportion of time relating to TDF factors associated with Opportunity, in comparison to Motivation, was found for the following RLOs: Using the phone and other devices, Communication tactics, Troubleshooting tips and Hearing aid retubing. The following RLOs included a high proportion of time relating to TDF factors associated with Motivation in comparison to Opportunity: Getting to know your hearing aids, How to insert your hearing aids, What to expect when wearing hearing aids, and Adapting to wearing hearing aids. Therefore, the C2Hear RLOs consisted of different "active ingredients", each associated with the different components of the COM-B model in order to facilitate the desired target behaviour (i.e. hearing aid use).

\section{Ecologically valid approach}

\section{Generating and labelling the $m R L O s$}

In total, the C2Hear RLOs were segmented into 42 mRLOs, with a mean average duration of one-minute (range $=20$-seconds, to 1 -minute and 56-seconds). Labels for each mRLO derived from the Think Aloud interviews took the format of a question in the first-person singular. In addition, from the theoretical phase of the development process, each mRLO could also be 
classified according to the COM-B model and TDF. In Table 2, an example is provided for the How to insert your hearing aids RLO, which was segmented into three mRLOs, each labelled in accordance with the Think Aloud data and mapped onto the TDF and COM-B model. Data for all remaining mRLOs are provided in Supplemental Materials 2.

During the Think Aloud interviews, participants consistently reported that the mRLOs could be clustered according to their likely need and use along the patient journey post-hearing aid fitting (i.e. categorised according to relevant information required before hearing aid fitting, immediately after fitting, and up to six-weeks post-fitting). As a result, the following five high-level categories were also generated from the Think Aloud data: (i) Using your hearing aids (which included mRLOs derived from the Getting to know your hearing aids and How to insert your hearing aids C2Hear RLOs); (ii) Getting used to your hearing aids (What to expect when wearing hearing aids; Adapting to wearing hearing aids); (iii) Looking after your hearing aids (Hearing aid care; Hearing aid retubing; Troubleshooting tips); (iv) Communication with others (Communication tactics); and (v) Using phones and other devices.

\section{Developing the mHealth delivery platform}

The collated feedback generated by users during each of the four development iterations is summarised in Supplementary Materials 3. Technical issues (e.g. unresponsive taps/swipes when making an mRLO selection) and problems associated with usability (e.g. requirement of a back button to improve navigation) were identified and addressed. The final m2Hear intervention comprises the following individualised and interactive components, which can also be viewed online via https://www.nottingham.ac.uk/helm/dev-test/m2hear/: 
i. Earmould coupling. On the initial landing page, there is an option to select either open fit or custom earmould hearing aids.

ii. Five high-level categories. The mRLOs are subdivided into five high-level categories corresponding to the patient journey pre- and post-hearing aid fitting, which were added in accordance with participants comments during the Think Aloud interviews.

iii. Series of $42 m R L O s$. Each $m R L O$ has a specific user-centred question, derived from the Think Aloud interviews (see Supplemental Materials 4). In addition, for increased individualisation, a 'Viewed videos' section is included and located at the bottom of each webpage so that the user can track when and how often an mRLO has been watched. This additional functionality was viewed favourably during iterative usability testing and was modified in accordance with feedback to improve usability (e.g. moved from the top of the screen to bottom, as the latter was considered less confusing and/or distracting).

iv. Activities. Adapted optional activities were developed, based on the most frequently viewed RLOs from the original RCT evaluation, namely, Getting to know your hearing aids and How to insert your hearing aids (Ferguson et al., 2016a). We also opted to include activities on communication tactics that had been developed as part of another mRLO project aimed at frequent communication partners (Ferguson et al., 2019b). Each activity aimed to reinforce the learning goal of the associated mRLO. For example, the learning goal of the mRLO for How do I put my hearing aids in? is to understand how to correctly insert the earmould and hearing aid. The associated activity requires the user to drag five photographic images, each showing different stages of insertion, into the correct order. Feedback is provided based on the user's response. For a video demonstration of this activity, see Supplemental Materials 4. A 
description of all activities developed and included in m2Hear is summarised in Table 3.

v. Quizzes. An optional multiple-choice question was associated with the learning goal of 34 associated mRLOs. Each quiz question provides feedback and additional supporting information depending on how the user responds. For example, the How do I put my hearing aids in? quiz question requires users to select one of three photographic images showing the earmould and hearing aid inserted correctly, and appropriate feedback is provided depending on how the user answers. For a video demonstration, see Supplemental Materials 5.

\section{DISCUSSION}

In the current paper we have described the development of an mHealth educational intervention designed specifically for first-time hearing aid users. Using a combined theoretical and ecological approach, we aimed to update our original C2Hear RLO-based intervention (Ferguson et al., 2016a), which provides limited opportunities for individualisation and interactivity due to the DVD-based mode of delivery. Our rationale for redevelopment was grounded in existing evidence that mHealth interventions improve selfmanagement of other chronic health conditions, primarily due to greater accessibility and opportunities for user engagement (Wang et al., 2014; Kim \& Lee, 2017). As a result, we have repurposed the C2Hear RLOs into a series of shorter mRLOs delivered via an mHealth platform, called m2Hear, to enhance learning potential through increased individualisation and interactivity. 
A key strength of the m2Hear development process was its theoretical underpinning. According to UK MRC (2006) guidance, it is important to draw on existing theory to understand the processes that are necessary to facilitate optimal health behaviour change. The value of such an approach is that it has the potential to increase the likelihood that complex healthcare interventions will be effective. Although previously developed educational interventions for hearing aid users have been shown to provide a range of patient benefits (Kramer et al., 2005; Lundberg et al., 2011; Thorén et al., 2014), they did not report whether existing theory and/or design principles were employed during the development process. In comparison, the design of our original C2Hear RLOs were theoretically underpinned by pedagogical principles to ensure that an appropriate multimedia environment was created (Wharrad \& Windle, 2010). The current study extends this original design approach, employing the contemporary COM-B model and TDF to identify the "active ingredients" of the original $\mathrm{C} 2 \mathrm{Hear}$ intervention that facilitate the target behaviour of hearing aid use.

An advantage of using the COM-B model and TDF, as opposed to other theories and models from health psychology, is that it is a framework that has been specifically designed to inform the development and evaluation of complex behaviour change interventions (Coulson et al., 2016). In the current study, through identification of specific intervention functions that facilitate the desired target behaviour (i.e. hearing aid use), we found that TDF factors associated with Capability (i.e. Knowledge, Physical skills, Behavioural regulation) featured strongly across all C2Hear RLOs. This was perhaps unsurprising, given that the original intervention aimed to improve knowledge of hearing aids and communication in first-time hearing aid users. In the original RCT that assessed the provision of the RLOs in first-time hearing aid users, knowledge was significantly improved, with large clinical effect sizes, which also led to a significant improvements in practical hearing aid handling skills, again 
with large clinical effect sizes (Ferguson et al., 2016a). The need to develop an educational intervention to facilitate these aspects of hearing loss self-management originated from existing findings that hearing aid users continue to experience difficulties after fitting, including problems associated with regular care and maintenance, as well as discomfort (McCormack \& Fortnum, 2013). This was subsequently confirmed in our Delphi review of hearing professional stakeholders (Ferguson et al., 2018).

Nevertheless, in addition to Capability, we also found that specific C2Hear RLOs incorporated topics relating to Opportunity (e.g. Social influences, Environmental context) and Motivation (e.g. Intentions, Reinforcement, Optimism, Beliefs about consequences). The importance of social and environmental factors in adult aural rehabilitation should not be underestimated, given that family and friends (or frequent communications partners) play a pivotal role in hearing loss self-management (Kamil \& Lin, 2015; Barker et al., 2017). Motivational factors, such as confidence (or self-efficacy) and readiness to use hearing aids, have also been shown to effect hearing aid outcomes, including use, benefit and satisfaction (West \& Smith, 2007; Dullard \& Cienkowski, 2014; Hickson et al., 2014; Kelly-Campbell \& McMillan, 2015; Ferguson et al., 2016b). Furthermore, in a registered RCT, providing $\mathrm{C} 2 \mathrm{Hear}$ at the hearing assessment was shown to improve knowledge of hearing aids and communication, as well as hearing aid self-efficacy when measured at hearing aid fitting (Gomez \& Ferguson, 2019). Whether this "early" provision would impact long-term hearing aid outcomes requires further investigation. By using the COM-B model as an underpinning framework, we can better understand how $\mathrm{C} 2 \mathrm{Hear}$, as well as m2Hear, likely facilitate hearing aid outcomes in first-time users. 
A further strength of our mHealth developmental process was that key stakeholder input from adults with lived experience of hearing loss was incorporated throughout. Similarly, the original C2Hear RLOs were also developed using a user-centred and participatory design approach; hearing aid users and hearing healthcare professionals were consulted throughout the development processes to ensure that the needs and experiences of the end user, as well as clinical validity, were captured (Ferguson et al., 2018). Adopting a similar approach in the development of m2Hear, after identifying the 42 shorter mRLOs with a specific learning goal, we then involved existing hearing aid users. They participated in Think Aloud interviews, describing the content of the individual mRLOs in their own words. This led to the generation of labels for each mRLO and ensured that the user's voice was embedded within the final mHealth intervention. An advantage of involving stakeholders in intervention development is that it can lead to the generation of engaging resources that are aligned with the specific needs and personal preferences of the end-user (O'Keefe et al., 2008). Thus, it was expected that this approach would subsequently improve usability and, ultimately, intervention effectiveness.

Following development, m2Hear was evaluated in a registered study (https://clinicaltrials.gov/, NCT03136718) to investigate the feasibility of the intervention in naïve first-time hearing aid users. Specifically, following approximately 10 -weeks of independent use in their everyday lives, we investigated delivery, accessibility, usability, acceptability, and adherence of m2Hear using a mixed-methods approach in first-time hearing aid users. Semi-structured interviews provided an in-depth insight into participant's experiences, with participants reporting that $\mathrm{m} 2 \mathrm{Hear}$ is a concise and comprehensive resource, enabling greater individualisation and independence to self-manage hearing loss, leading to empowerment to better manage hearing aids and communication (Ferguson, 2019; 
Maidment et al., in press). Patient-reported outcome measures also showed a range of benefits of $\mathrm{m} 2 \mathrm{Hear}$ when used in conjunction with hearing aids, including improved hearingrelated quality of life, hearing aid self-efficacy, social participation, as well as knowledge of hearing aids and communication (Ferguson et al., 2019a; Ferguson et al., in press). In addition, usability was rated highly and most participants agreed that m2Hear was pitched at the right level. These latter findings likely reflect the high levels of user-involvement in the development.

The next stage in the evaluation process would be to assess the effectiveness of m2Hear versus standard aural rehabilitation practices in an RCT. A future RCT might consider evaluating $\mathrm{m} 2 \mathrm{Hear}$ as a single intervention and/or as part of a comprehensive package that also incorporates additional elements that have also been identified to support successful selfmanagement, such as monitoring, psychosocial factors, cues to action and collaborative decision-making (Barker et al., 2016b; Convery et al., 2018; Convery et al., 2019).

\section{Study limitation}

Despite these strengths, we acknowledge that our development process may be limited in its generalisability. Namely, in the user-centred, participatory design approach employed in the current study, hearing aid users were recruited from the NIHR Nottingham BRC participant database. Most individuals in this database are current or former patients of the Adult Audiology Service at Nottingham University Hospitals NHS Trust. As a result, the findings derived from our ecologically valid methods might be limited in their application to other clinical settings. Nevertheless, despite this potential confound, m2Hear would likely be appropriate for patients based throughout the UK, as well as internationally. 


\section{Clinical Implications}

Form a UK perspective, the provision of high-quality information has been endorsed in national quality standards for adult aural rehabilitation (National Institute for Health and Care Excellence, 2018). Subsequently, over 40 NHS and independent sector audiology services based in the UK have started implementing the C2Hear RLOs into their clinical practices. In addition, since its launch in November 2015, the C2Hear YouTube channel (https://www.youtube.com/c2hearonline) has received over 260,000 unique views, $70 \%$ of which originate from other countries, including the United States of America (USA) (31\%), India (9\%) and Canada (3\%). While some of the RLO content might be more appropriate for UK-based patients, the RLOs can be easily adapted for international audiences. For example, the C2Hear RLOs have been modified for patients living in the USA (i.e. voice over and subtitles in American English), and have subsequently been incorporated into a "bestpractices" hearing intervention evaluated as part of the Aging and Cognitive Health Evaluation in Elders (ACHIEVE) study (Deal et al., 2018).

\section{Conclusions}

Taken together, this research has resulted in the development of theoretically driven, usercentred mHealth intervention that can be delivered through mobile technologies to support self-management of hearing loss in first-time hearing aid users. Called m2Hear, this novel mHealth educational intervention provides opportunities for individualised learning and encourages greater interaction. Given that the use of mobile technologies in hearing healthcare is expected to continue to rise, there is a clear opportunity for audiologists worldwide to harness mHealth to improve access to hearing healthcare. In the present paper, we have argued that a key area where mHealth technologies are advantageous is through the delivery of remotely-delivered educational information that can be individualised and is more 
interactive compared to previously developed materials (Kramer et al., 2005; Thorén et al., 2014; Ferguson et al., 2016a; Gomez \& Ferguson, 2019). On this basis, mHealth educational interventions have the potential to facilitate a more patient-centred approach, empowering patients to be more active participants in the management of their hearing health. The extent to which mHealth educational interventions can reduce the time needed for audiologists to verbally disseminate large volumes of information to patients during clinical appointments also warrants investigation. Therefore, further research is necessary to confirm whether the additional functionality afforded by $\mathrm{m} 2 \mathrm{Hear}$ leads to improved hearing outcomes in comparison to standard aural rehabilitation practices,.

\section{ACKNOWLEDGMENTS}

We would like to thank Lydia Jones and the Health eLearning \& Media (HELM) team at University of Nottingham for their pedagogical and technical input to the development of m2Hear. We also wish to acknowledge the insightful input from our patient and public involvement panel (Julia Brown, Veronica Colley, Claire Ward), as well as all participants who took part in the research, who helped us to embed the patient voice in the development of m2Hear. This paper presents independent research funded by the NIHR Nottingham Biomedical Research Centre under its Research for Patient Benefit (RfPB) Program (Grant Reference Number PB-PG-0815-20019) and was carried out at the NIHR Nottingham Clinical Research Facilities. The views expressed are those of the authors and not necessarily those of the NHS, the NIHR or the Department of Health and Social Care. 
CONFLICTS OF INTEREST

None. 


\section{REFERENCES}

Barker A., Leighton P. \& Ferguson M. 2017. Coping together with hearing loss: a qualitative meta-synthesis of the psychosocial experiences of people with hearing loss and their communication partners. International Journal of Audiology, 56, 297-305.

Barker F., Atkins L. \& de Lusignan S. 2016a. Applying the COM-B behaviour model and Behaviour Change Wheel to develop an intervention to improve hearing aid use in adult auditory rehabilitation. International Journal of Audiology, 55, S90-S98.

Barker F., Mackenzie E., Elliott L., Jones S. \& de Lusignan S. 2016b. Interventions to improve hearing aid use in adult auditory rehabilitation. Cochrane Database of Systematic Reviews, CD010342.

Bennett R.J., Meyer C.J., Eikelboom R.H. \& Atlas M.D. 2018. Investigating the knowledge, skills, and tasks required for hearing aid management: perspectives of clinicians and hearing aid owners. American Journal of Audiology, 27, 67-84.

Braun V. \& Clarke V. 2006. Using thematic analysis in psychology. Qualitative Research in Psychology, 3, 77-101.

British Society of Audiology 2016. Practice guidance: common principles of rehabilitation for adults in audiology services. Bathgate, United Kingdom.

Caposecco A., Hickson L. \& Meyer C. 2014. Hearing aid user guides: Suitability for older adults. International Journal of Audiology, 53, S43-S51.

Caposecco A., Hickson L., Meyer C. \& Khan A. 2016. Evaluation of a modified user guide for hearing aid management. Ear and Hearing, 37, 27-37.

Convery E., Hickson L., Meyer C. \& Keidser G. 2019. Predictors of hearing loss selfmanagement in older adults. Disability and Rehabilitation, 41, 2026-2035.

Convery E., Meyer C., Keidser G. \& Hickson L. 2018. Assessing hearing loss selfmanagement in older adults. International Journal of Audiology, 57, 313-320.

Coulson N., Ferguson M.A., Henshaw H. \& Heffernan E. 2016. Applying theories of health behaviour and change to hearing health research: time for a new approach. International Journal of Audiology, 55, S99-S104.

Deal J.A., Goman A.M., Albert M.S., Arnold M.L., Burgard S., et al. 2018. Hearing treatment for reducing cognitive decline: Design and methods of the Aging and Cognitive Health Evaluation in Elders randomized controlled trial. Alzheimer's and Dementia: Translational Research and Clinical Interventions, 4, 499-507. 
Deloitte UK 2019. Plateauing at the peak: the state of the smartphone, 2019. London, United Kingdom.

Dullard B.A. \& Cienkowski K.M. 2014. Exploring the relationship between hearing aid selfefficacy and hearing aid management. Perspectives on Aural Rehabilitation Its Instrumentation, 21, 56-62.

Evans C. \& Gibbons N. 2007. The interactivity effect in multimedia learning. Computers Education, 49, 1147-1160.

Ferguson M.A. 2019. mHealth technologies empower users of hearing healthcare. ENT \& Audiology News, 28.

Ferguson M.A., Brandreth M., Brassington W. \& Wharrad H. 2015. Information retention and overload in first-time hearing aid users: an interactive multimedia educational solution. American Journal of Audiology, 24, 329-332.

Ferguson M.A., Brandreth M., Leighton P., Brassington W. \& Wharrad H. 2016a. A randomized controlled trial to evaluate the benefits of a multimedia educational programme for first-time hearing aid users. Ear and Hearing, 37, 123-136.

Ferguson M.A., Brandreth M., Leighton P. \& Wharrad H. 2018. Development of a multimedia educational programme for first-time hearing aid users: a participatory approach. International Journal of Audiology, 57, 600-609.

Ferguson M.A., Kitterick P.T., Chong L.Y., Edmondson-Jones M., Barker F., et al. 2017. Hearing aids for mild to moderate hearing loss in adults. Cochrane Database of Systematic Reviews, 9, CD012023.

Ferguson M.A., Maidment D., Henshaw H. \& Heffernan E. 2019a. Evidence-based interventions for adult auditory rehabilitation: that was then, this is now. Seminars in Hearing, 40, 68-84.

Ferguson M.A., Maidment D.W., Gomez R., Coulson N.C. \& Wharrad H. in press. The feasibility of an $\mathrm{m}$-health educational programme to improve outcomes in first-time hearing aid users. International Journal of Audiology.

Ferguson M.A., Maidment D.W., Henshaw H. \& Gomez R. 2019b. Knowledge is power: improving outcomes for patients, partner and professionals in the digital age. Perspectives of the ASHA Special Interest Groups, 4, 140-148.

Ferguson M.A., Woolley A. \& Munro K.J. 2016b. The impact of self-efficacy, expectations and readiness on hearing aid outcomes. International Journal of Audiology, 55, S34S41. 
Fonteyn M.E., Kuipers B. \& Grobe S.J. 1993. A description of think aloud method and protocol analysis. Qualitative Health Research, 3, 430-441.

Gomez R. \& Ferguson M.A. 2019. Improving knowledge and self-efficacy for hearing aids self-management: the early delivery of a multimedia-based education program in firsttime adult hearing aid users. International Journal of Audiology, DOI: 10.1080/14992027.14992019.11677953.

Henshaw H., Clark D., Kang S. \& Ferguson M.A. 2012. Computer skills and Internet use in adults aged 50-74 years: influence of hearing difficulties. Journal of Medical Internet Research, 14, e113.

Hickson L., Meyer C., Lovelock K., Lampert M. \& Khan A. 2014. Factors associated with success with hearing aids in older adults. International Journal of Audiology, 53, S18S27.

Kamil R.J. \& Lin F.R. 2015. The effects of hearing impairment in older adults on communication partners: a systematic review. Journal of the American Academy of Audiology, 26, 155-182.

Kelly-Campbell R.J. \& McMillan A. 2015. The relationship between hearing aid self-efficacy and hearing aid satisfaction. American Journal of Audiology, 24, 529-535.

Kim B.Y. \& Lee J. 2017. Smart devices for older adults managing chronic disease: a scoping review. JMIR mHealth and uHealth, 5, e69.

Kochkin S., Beck D.L., Christensen L.A., Compton-Conley C., Fligor B.J., et al. 2010. MarkeTrak VIII: The impact of the hearing healthcare professional on hearing aid user success. Hearing Review, 17, 12-34.

Kramer S.E., Allessie G.H.M., Dondorp A.W., Zekveld A.A. \& Kapteyn T.S. 2005. A home education program for older adults with hearing impairment and their significant others: A randomized trial evaluating short- and long-term effects. International Journal of Audiology, 44, 255-264.

Lundberg M., Andersson G. \& Lunner T. 2011. A randomized, controlled trial of the shortterm effects of complementing an educational program for hearing aid users with telephone consultations. Journal of the American Academy of Audiology, 22, 654-662.

Maidment D.W., Ali Y.H.K. \& Ferguson M.A. 2019. Applying the COM-B model to assess the usability of smartphone-connected listening devices in adults with hearing loss. Journal of the American Academy of Audiology, 30, 417-430.

Maidment D.W., Heyes R., Gomez R., Coulson N.C., Wharrad H., et al. in press. Evaluating a theoretically informed and co-created mHealth educational intervention for firsttime hearing aid users: a qualitative interview study. JMIR mHealth and uHealth. 
McCormack A. \& Fortnum H. 2013. Why do people fitted with hearing aids not wear them? International Journal of Audiology, 52, 360-368.

McMullan A., Kelly-Campbell R.J. \& Wise K. 2018. Improving hearing aid self-efficacy and utility through revising a hearing aid user guide: A pilot study. American Journal of Audiology, 27, 45-56.

Medical Research Council 2006. Developing and evaluating complex interventions: new guidance. London, United Kingdom

Michie S., van Stralen M. \& West R. 2011. The Behaviour Change Wheel: a new method for characterising and designing behaviour change interventions. Implementation Science, 6,42 .

National Institute for Health and Care Excellence 2018. Hearing loss in adults: assessment and management. London, United Kingdom

O'Keefe M., O'Regan L. \& Cashman D. 2008. Supporting the development of Communities of Practice: informal versus formal communities Association for Learning Technology conference, 'Rethinking the Digital Divide' University of Leeds, UK.

Office for National Statistics. (2017). Internet users in the UK: 2017. Retrieved from https://www.ons.gov.uk/businessindustryandtrade/itandinternetindustry/bulletins/inter netusers/2017

Patton M. 1990. Purposeful sampling. Qualitative evaluation and research methods, 2, 169186.

Reese J.L. \& Smith S.L. 2006. Recall of hearing aid orientation content by first-time hearing aid users. Seminars in Hearing, 27, 337-344.

Thorén E.S., Öberg M., Wänström G., Andersson G. \& Lunner T. 2014. A randomized controlled trial evaluating the effects of online rehabilitative intervention for adult hearing-aid users. International Journal of Audiology, 53, 452-461.

Todhunter F. 2015. Using concurrent think-aloud and protocol analysis to explore student nurses' social learning information communication technology knowledge and skill development. Nurse Education Today, 35, 815-822.

Wang J., Wang Y., Wei C., Yao N., Yuan A., et al. 2014. Smartphone interventions for longterm health management of chronic diseases: an integrative review. Telemedicine and e-Health, 20, 570-583.

West R. \& Smith S.L. 2007. Development of a hearing aid self-efficacy questionnaire. International Journal of Audiology, 46, 759-771. 
Wharrad H. \& Windle R. 2010. Case studies of creating reusable inter professional e-learning objects. In: Bromage A, Clouder L, Gordon F \& T. J (eds.) Interprofessional ELearning and Collaborative Work: Practices and Technologies: Practices and Technologies: IGI Global.

Windle R.J., McCormick D., Dandrea J. \& Wharrad H. 2011. The characteristics of reusable learning objects that enhance learning: a case-study in health-science education. British Journal of Educational Technology, 42, 811-823.

Zhang D., Zhou L., Briggs R.O. \& Nunamaker J.F. 2006. Instructional video in e-learning: Assessing the impact of interactive video on learning effectiveness. Information and Management, 43, 15-27. 


\section{FIGURES}

\begin{tabular}{|c|c|c|c|c|}
\hline \multicolumn{5}{|c|}{$\begin{array}{l}\text { NAME OF RLO: How to insert your hearing } \\
\text { NAME OF RESEARCHER: Maidment DW }\end{array}$} \\
\hline \multirow{2}{*}{ COM-B } & \multirow{2}{*}{ TDF } & \multicolumn{2}{|c|}{ When } & \multirow{2}{*}{$\begin{array}{l}\text { Description } \\
\text { (optional) }\end{array}$} \\
\hline & & Start & Finish & \\
\hline \multirow[t]{4}{*}{ CAPABILITY } & KNOWLEDGE & $\begin{array}{l}0: 32 \\
1: 50 \\
2: 51\end{array}$ & $\begin{array}{l}0: 36 \\
2: 51 \\
3: 20\end{array}$ & $\begin{array}{l}\text { What happens if you don't } \\
\text { insert correctly }\end{array}$ \\
\hline & SKILS & $\begin{array}{l}0: 22 \\
0: 32 \\
0: 44 \\
1: 04 \\
3: 21\end{array}$ & $\begin{array}{l}0: 32 \\
0: 38 \\
0: 57 \\
1: 31 \\
3: 48\end{array}$ & How to insert \\
\hline & $\begin{array}{l}\text { MEMORY, ATTENTION AND } \\
\text { DECISION PROCESSES }\end{array}$ & $\begin{array}{l}0: 38 \\
0: 58\end{array}$ & $\begin{array}{l}0: 44 \\
1: 04\end{array}$ & $\begin{array}{l}\text { Recognise shape } \\
\text { Cup of tea }\end{array}$ \\
\hline & BEHAVIOURAL REGULATION & $\begin{array}{l}1: 32 \\
2: 35 \\
3: 49\end{array}$ & $\begin{array}{l}1: 50 \\
2: 51 \\
4: 08\end{array}$ & $\begin{array}{l}\text { Check ear mould } \\
\text { Takes time } \\
\text { Don't forget... }\end{array}$ \\
\hline \multirow[t]{2}{*}{ OPPORTUNITY } & SOCIAL INFLUENCES & $\begin{array}{l}2: 18 \\
2: 40 \\
4: 10 \\
\end{array}$ & $\begin{array}{l}2: 23 \\
2: 51 \\
4: 20\end{array}$ & $\begin{array}{l}\text { Others hear whistling } \\
\text { Ear mould reshaped } \\
\text { Family/friend to assist }\end{array}$ \\
\hline & $\begin{array}{l}\text { ENVIRONMENTAL CONTEXT } \\
\text { AND RESOURCES }\end{array}$ & $\begin{array}{l}2: 01 \\
2: 30\end{array}$ & $\begin{array}{l}2: 24 \\
2: 34\end{array}$ & $\begin{array}{l}\text { Whistling } \\
\text { Soreness }\end{array}$ \\
\hline \multirow[t]{8}{*}{ MOTIVATION } & $\begin{array}{l}\text { SOCIAL/PROFESSIONAL ROLE \& } \\
\text { IDENTITY }\end{array}$ & & & \\
\hline & BELIEFS ABOUT CAPABILITIES & & & \\
\hline & $\begin{array}{l}\text { BELIEFS ABOUT } \\
\text { CONSEQUENCES }\end{array}$ & & & \\
\hline & INTENTIONS & & & \\
\hline & GOALS & & & \\
\hline & REINFORCEMENT & $\begin{array}{l}0: 56 \\
1: 40 \\
1: 55 \\
2: 12 \\
2: 56 \\
3: 09 \\
\end{array}$ & $\begin{array}{l}1: 03 \\
1: 51 \\
2: 01 \\
2: 29 \\
3: 04 \\
3: 24 \\
\end{array}$ & Ticks/crosses \\
\hline & EMOTION & & & \\
\hline & OPTIMISM & $\begin{array}{l}2: 35 \\
3: 59\end{array}$ & $\begin{array}{l}2: 40 \\
4: 08\end{array}$ & $\begin{array}{c}\text { Don't give up/practice makes } \\
\text { perfect }\end{array}$ \\
\hline
\end{tabular}

Figure 1. Example of a completed coding sheet, whereby the start and finish times within an RLO corresponding to the COM-B model and Theoretical Domains Framework (TDF) were recorded. 


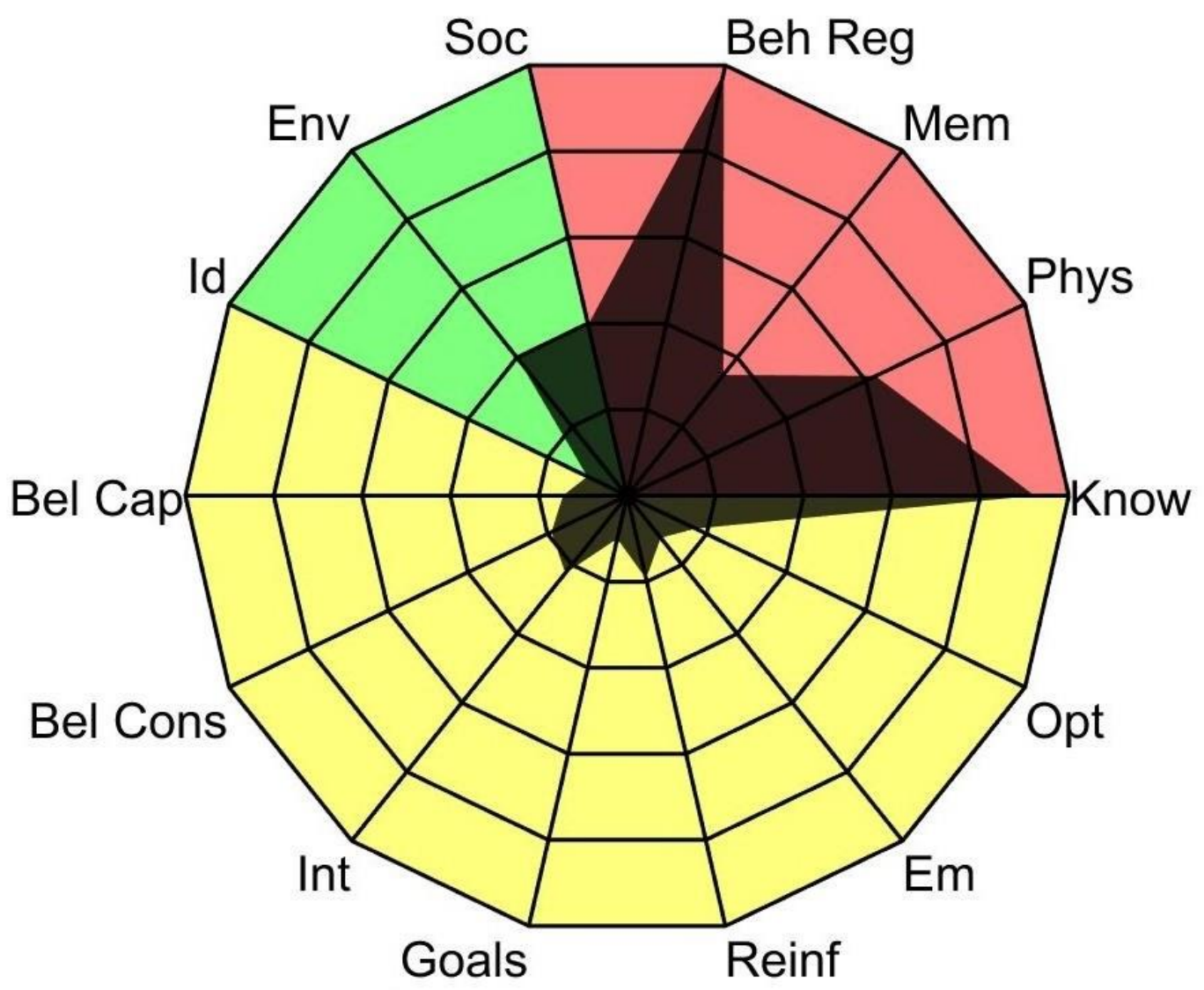

\section{Capability $\square$ Opportunity $\square$ Motivation}

Figure 2. Radar chart showing the percentage of time each TDF factor was included, on average, across all C2Hear RLOs. Percentages are plotted for each TDF factor on individual axes. Concentric grid lines connecting axes increase in 10\% increments, from $0 \%$ (centre point) to $50 \%$ (outer edge). The plotted percentages for each TDF factor are connected and the area formed has been shaded in black. Know= Knowledge; Phys= Physical skill; Mem= Memory, decision and attention; Beh Reg= Behavioural regulation; $\operatorname{Soc}=$ Social influences; Env= Environmental context; $\mathrm{Id}=$ Social identity; Bel Cap= Beliefs about capabilities; Bel Cons= Beliefs about consequences; Int= Intentions; Reinf $=$ Reinforcement $; \mathrm{Em}=$ Emotion; $\mathrm{Opt}=$ Optimism. 

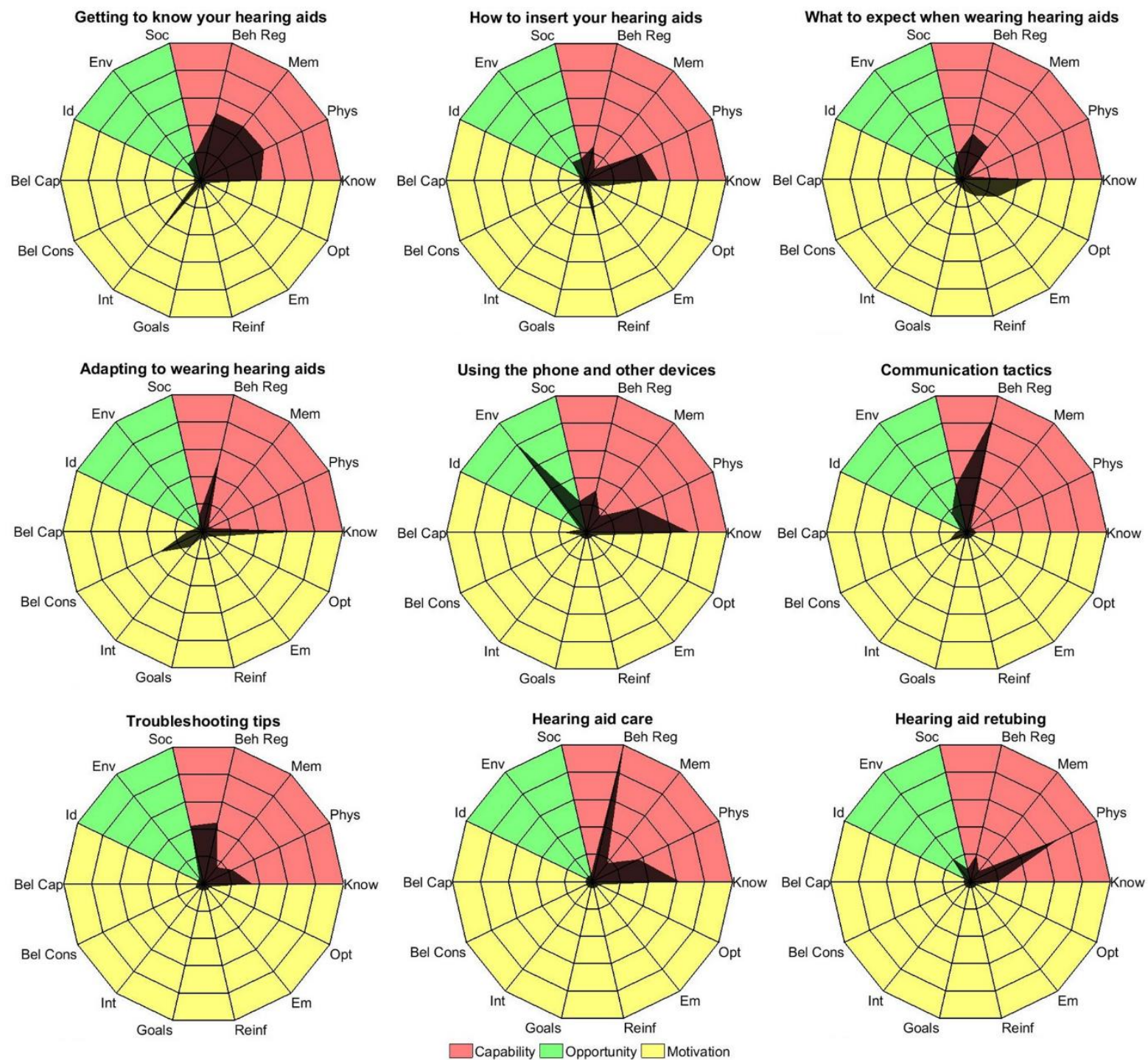

Figure 3. Radar charts showing the percentage of time the TDF factors were included within each C2Hear RLO. Percentages are plotted for each TDF factor on individual axes. Concentric grid lines connecting axes increase in $20 \%$ increments, from $0 \%$ (centre point) to $100 \%$ (outer edge). The plotted percentages for each TDF factor are connected and the area formed has been shaded in black. 


\section{TABLES}

Table 1. Demographic information of Think Aloud participants.

\begin{tabular}{lrl}
\hline Gender & n \\
& Male & 4 \\
Fge & Female & 11 \\
\hline & Years \\
& Mean (SD) & $64.67(11.46)$ \\
Range & $42-84$ \\
\hline Estimated hearing loss duration & Years \\
\hline Mean (SD) & $16.19(13.25)$ \\
& Range & $<1-49$ \\
\hline & n \\
\hline Retired & 11 \\
Employed & 4 \\
\hline
\end{tabular}

Table 2. The How to insert your hearing aids C2Hear RLO segmented into three mRLOs, with corresponding labels and coded with the appropriate Theoretical Domains Framework (TDF) and COM-B model.

\begin{tabular}{|c|c|c|c|c|}
\hline \multicolumn{2}{|c|}{$\begin{array}{l}\text { C2Hear RLO timing } \\
\text { (minute : second) }\end{array}$} & $\begin{array}{l}\text { mRLO label derived from } \\
\text { Think Aloud interviews }\end{array}$ & TDF & COM-B \\
\hline \multirow[t]{2}{*}{$0: 19$} & \multirow[t]{2}{*}{$1: 51$} & \multirow[t]{2}{*}{ How do I put my hearing aids in? } & $\begin{array}{l}\text { Knowledge; } \\
\text { Physical skills; }\end{array}$ & Capability \\
\hline & & & Reinforcement & Motivation \\
\hline \multirow{2}{*}{$3: 25$} & \multirow{2}{*}{$4: 30$} & \multirow{2}{*}{$\begin{array}{l}\text { How do I take my hearing aids } \\
\text { out? }\end{array}$} & $\begin{array}{l}\text { Knowledge; } \\
\text { Physical skills; }\end{array}$ & Capability \\
\hline & & & Reinforcement & Motivation \\
\hline $1: 52$ & $3: 20$ & $\begin{array}{l}\text { What can go wrong if I don't put } \\
\text { in my hearing aids correctly? }\end{array}$ & $\begin{array}{l}\text { Social influences; } \\
\text { Environmental context }\end{array}$ & Opportunity \\
\hline
\end{tabular}

Table 3. A summary of the developed activities $(n=6)$ included in the m2Hear intervention. 
Development of an mHealth intervention

\begin{tabular}{ll}
\hline Title & Description \\
\hline $\begin{array}{l}\text { Labelling the components (e.g. battery compartment, } \\
\text { programme switch) of the hearing aid }\end{array}$ & Drag and drop \\
How to correctly insert the earmold and hearing aid & Drag and drop \\
How to clean the earmold and hearing aid & Drag and drop \\
How to improve taking part in conversations & $\begin{array}{l}\text { User-defined text input } \\
\text { Controlling the environment: Restaurant game }\end{array}$ \\
Hearing problems and potential solutions & $\begin{array}{l}\text { Selecting where to sit in a virtual } \\
\text { restaurant to optimise communication }\end{array}$ \\
\hline
\end{tabular}




\section{SUPPLEMENTAL MATERIALS}

Supplemental Materials 1. Definitions of the Theoretical Domains Framework (TDF).

\begin{tabular}{|c|c|c|}
\hline COM-B component & Theoretical Domain & Definition \\
\hline \multirow[t]{4}{*}{ Capability } & Knowledge & An awareness of the existence of something. \\
\hline & Physical skills & An ability or proficiency acquired through practice. \\
\hline & Memory, attention \& decision processes & $\begin{array}{l}\text { The ability to retain information, focus selectively on aspects of the } \\
\text { environment and choose between two or more alternatives. }\end{array}$ \\
\hline & Behavioural regulation & $\begin{array}{l}\text { Anything aimed at managing or changing objectively observed or } \\
\text { measured actions. }\end{array}$ \\
\hline \multirow[t]{2}{*}{ Opportunity } & Social influences & $\begin{array}{l}\text { Those interpersonal processes that can cause individuals to change their } \\
\text { thoughts, feelings, or behaviours. }\end{array}$ \\
\hline & Environmental context \& resources & $\begin{array}{l}\text { Any circumstance of a person's situation or environment that } \\
\text { discourages or encourages the development of skills and abilities, } \\
\text { independence, social competence, and adaptive behaviour. }\end{array}$ \\
\hline \multirow[t]{8}{*}{ Motivation } & Social/professional role \& identity & $\begin{array}{l}\text { A coherent set of behaviours and displayed personal qualities of an } \\
\text { individual in a social or work setting. }\end{array}$ \\
\hline & Beliefs about capabilities & $\begin{array}{l}\text { Acceptance of the truth, reality, or validity about an ability or facility } \\
\text { that a person can put to a constructive use. }\end{array}$ \\
\hline & Beliefs about consequences & $\begin{array}{l}\text { Acceptance of the truth, reality, or validity about outcomes of a } \\
\text { behaviour in a given situation. }\end{array}$ \\
\hline & Intentions & $\begin{array}{l}\text { A conscious decision to perform a behaviour or a resolve to act in a } \\
\text { certain way. }\end{array}$ \\
\hline & Goals & $\begin{array}{l}\text { Mental representation of outcomes or end states that an individual wants } \\
\text { to achieve. }\end{array}$ \\
\hline & Reinforcement & $\begin{array}{l}\text { Increasing the probability of a response by arranging a dependent } \\
\text { relationship, or contingency, between the response and a given stimulus. }\end{array}$ \\
\hline & Emotion & $\begin{array}{l}\text { A complex reaction pattern, involving experiential, behavioural, and } \\
\text { physiological elements, by which the individual attempts to deal with a } \\
\text { personally significant matter or event }\end{array}$ \\
\hline & Optimism & $\begin{array}{l}\text { The confidence that things will happen for the best or that desired goals } \\
\text { will be attained. }\end{array}$ \\
\hline
\end{tabular}


Supplemental Materials 2. Repurposing of the original C2Hear RLOs into mobile-enhanced RLOs (mRLOs). Each RLO was divided into shorter mRLOs (approximate timings provided) by the research team. A label for each mRLO was derived from Think Aloud interviews with existing hearing aid users to obtain their real-world perspectives. Each mRLO was also classified according to the theoretical domains framework (TDF), which links to one of the components from the COM-B model (capability, opportunity, motivation).

\begin{tabular}{|c|c|c|c|c|c|c|}
\hline \multirow{2}{*}{ C2Hear RLO } & \multicolumn{2}{|c|}{$\begin{array}{l}\text { mRLO timings } \\
\text { (minute : seconds) }\end{array}$} & \multirow{2}{*}{ mRLO label } & \multirow{2}{*}{ Category } & \multirow{2}{*}{ TDF } & \multirow{2}{*}{ COM-B } \\
\hline & Start & Finish & & & & \\
\hline \multirow{10}{*}{$\begin{array}{l}\text { Getting to know your hearing aids } \\
\text { https://youtu.be/rSYFRabR1VU }\end{array}$} & $0: 39$ & $1: 16$ & $\begin{array}{l}\text { How do I know which hearing } \\
\text { aid is for my left/right ear? }\end{array}$ & \multirow{10}{*}{$\begin{array}{l}\text { Using your hearing } \\
\text { aids }\end{array}$} & $\begin{array}{l}\text { Knowledge; } \\
\text { Physical skills }\end{array}$ & Capability \\
\hline & $0: 21$ & $0: 28$ & How do I turn my hearing aids on & & Knowledge; & Canability \\
\hline & $1: 20$ & $1: 54$ & and off? & & Physical skills & \\
\hline & $5: 57$ & 7:04 & $\begin{array}{l}\text { How do I change programmes on } \\
\text { my hearing aids? }\end{array}$ & & $\begin{array}{l}\text { Knowledge; } \\
\text { Physical skills }\end{array}$ & Capability \\
\hline & $0: 21$ & $0: 28$ & \multirow{2}{*}{$\begin{array}{l}\text { How do I change the volume on } \\
\text { my hearing aids? }\end{array}$} & & Knowledge; & \multirow{2}{*}{ Capability } \\
\hline & $7: 15$ & $7: 50$ & & & Physical skills & \\
\hline & $1: 55$ & $2: 29$ & $\begin{array}{l}\text { How do I keep my hearing aids } \\
\text { safe? }\end{array}$ & & $\begin{array}{c}\text { Knowledge; } \\
\text { Behavioural regulation; } \\
\text { Intentions }\end{array}$ & $\begin{array}{l}\text { Capability } \\
\text { Motivation }\end{array}$ \\
\hline & $2: 29$ & $3: 23$ & $\begin{array}{l}\text { How do I change my hearing aid } \\
\text { battery? }\end{array}$ & & $\begin{array}{l}\text { Knowledge; } \\
\text { Physical skills; } \\
\text { Intentions }\end{array}$ & $\begin{array}{l}\text { Capability } \\
\text { Motivation }\end{array}$ \\
\hline & $3: 24$ & $4: 24$ & $\begin{array}{l}\text { When should I change my } \\
\text { hearing aid battery? }\end{array}$ & & $\begin{array}{c}\text { Knowledge; } \\
\text { Memory, attention \& } \\
\text { decision processes; } \\
\text { Behavioural regulation }\end{array}$ & Capability \\
\hline & $4: 25$ & $5: 21$ & $\begin{array}{l}\text { How do I get more hearing aid } \\
\text { batteries? }\end{array}$ & & $\begin{array}{c}\text { Knowledge; } \\
\text { Behavioural regulation }\end{array}$ & Capability \\
\hline \multirow{3}{*}{$\begin{array}{l}\text { How to insert your hearing aids } \\
\text { https://youtu.be/8x130O7F7rM }\end{array}$} & $0: 19$ & $1: 51$ & How do I put my hearing aids in? & \multirow{3}{*}{$\begin{array}{l}\text { Using your hearing } \\
\text { aids }\end{array}$} & $\begin{array}{c}\text { Knowledge; } \\
\text { Physical skills; }\end{array}$ & Capability \\
\hline & & & & & Reinforcement & Motivation \\
\hline & $3: 25$ & $4: 30$ & & & Knowledge; & Capability \\
\hline
\end{tabular}




\begin{tabular}{|c|c|c|c|c|c|c|}
\hline & \multirow{2}{*}{\multicolumn{3}{|c|}{$\begin{array}{l}\text { How do I take my hearing aids } \\
\text { out? }\end{array}$}} & \multicolumn{3}{|c|}{ Physical skills; } \\
\hline & & & & & Reinforcement & Motivation \\
\hline & $1: 52$ & $3: 20$ & $\begin{array}{l}\text { What can go wrong if I don't put } \\
\text { in my hearing aids correctly? }\end{array}$ & & $\begin{array}{c}\text { Social influences; } \\
\text { Environmental context }\end{array}$ & Opportunity \\
\hline \multirow{3}{*}{$\begin{array}{l}\text { What to expect when wearing } \\
\text { hearing aids } \\
\text { https://youtu.be/ZM3S1bO_y } 9 \mathrm{w}\end{array}$} & $1: 08$ & $1: 32$ & \multirow{2}{*}{$\begin{array}{l}\text { What can I expect when wearing } \\
\text { hearing aids for the first time? }\end{array}$} & \multirow{6}{*}{$\begin{array}{l}\text { Getting used to your } \\
\text { hearing aids }\end{array}$} & \multirow{2}{*}{ Reinforcement } & \multirow{2}{*}{ Motivation } \\
\hline & $2: 48$ & 3:08 & & & & \\
\hline & $1: 33$ & $1: 48$ & $\begin{array}{l}\text { How do I get used to wearing my } \\
\text { hearing aids? }\end{array}$ & & Behavioural regulation & Capability \\
\hline \multirow{3}{*}{$\begin{array}{l}\text { Adapting to wearing hearing aids } \\
\underline{\text { https://youtu.be/p36SdxfmZrc }}\end{array}$} & $1: 06$ & $1: 47$ & \multirow{2}{*}{$\begin{array}{l}\text { Why should I wear my hearing } \\
\text { aids regularly? }\end{array}$} & & \multirow{2}{*}{$\begin{array}{c}\text { Knowledge; } \\
\text { Behavioural regulation; } \\
\text { Beliefs about consequences }\end{array}$} & Capability \\
\hline & $2: 19$ & $3: 24$ & & & & Motivation \\
\hline & $\begin{array}{l}0: 17 \\
2: 25 \\
4: 01\end{array}$ & $\begin{array}{l}0: 49 \\
2: 46 \\
4: 41\end{array}$ & $\begin{array}{l}\text { Why does it take time to get used } \\
\text { to wearing my hearing aids? }\end{array}$ & & Knowledge & Capability \\
\hline \multirow{3}{*}{$\begin{array}{l}\text { Hearing aid care } \\
\text { https://youtu.be/V2UEJfhjRMM }\end{array}$} & $0: 47$ & $1: 29$ & $\begin{array}{l}\text { How do I clean my hearing aid } \\
\text { earmold and tubing? }\end{array}$ & \multirow{9}{*}{$\begin{array}{l}\text { Looking after your } \\
\text { hearing aids }\end{array}$} & $\begin{array}{c}\text { Knowledge; } \\
\text { Behavioural regulation }\end{array}$ & Capability \\
\hline & $\begin{array}{l}0: 18 \\
2: 10\end{array}$ & $\begin{array}{l}0: 46 \\
2: 15\end{array}$ & $\begin{array}{l}\text { When do I clean my hearing aid } \\
\text { earmold and tubing? }\end{array}$ & & $\begin{array}{c}\text { Knowledge; } \\
\text { Memory, attention \& } \\
\text { decision processes }\end{array}$ & Capability \\
\hline & $1: 36$ & 2:09 & $\begin{array}{l}\text { When should I change my } \\
\text { hearing aid tubing? }\end{array}$ & & $\begin{array}{c}\text { Memory, attention \& } \\
\text { decision processes; } \\
\text { Behavioural regulation }\end{array}$ & Capability \\
\hline $\begin{array}{l}\text { Hearing aid retubing } \\
\text { https://youtu.be/A-pDNznoN3c }\end{array}$ & $0: 32$ & $2: 28$ & $\begin{array}{l}\text { How do I change my hearing aid } \\
\text { tubing? }\end{array}$ & & $\begin{array}{l}\text { Knowledge; } \\
\text { Physical skills }\end{array}$ & Capability \\
\hline \multirow{5}{*}{$\begin{array}{l}\text { Troubleshooting tips } \\
\underline{\text { https://youtu.be/ifLlbCV_Obw }}\end{array}$} & $1: 30$ & $2: 53$ & $\begin{array}{l}\text { What should I do if I can't hear } \\
\text { sound through my hearing aids? }\end{array}$ & & $\begin{array}{c}\text { Knowledge; } \\
\text { Behavioural regulation }\end{array}$ & Capability \\
\hline & $2: 54$ & $3: 41$ & $\begin{array}{l}\text { What should I do if my hearing } \\
\text { aids whistle (feedback)? }\end{array}$ & & $\begin{array}{c}\text { Knowledge; } \\
\text { Behavioural regulation }\end{array}$ & Capability \\
\hline & $3: 42$ & $4: 16$ & $\begin{array}{l}\text { What should I do if my hearing } \\
\text { aids are buzzing? }\end{array}$ & & $\begin{array}{c}\text { Physical skills; } \\
\text { Behavioural regulation }\end{array}$ & Capability \\
\hline & $4: 17$ & $4: 37$ & $\begin{array}{l}\text { What should I do if my earmold } \\
\text { causes me pain or discomfort? }\end{array}$ & & $\begin{array}{l}\text { Behavioural regulation } \\
\text { Social influences }\end{array}$ & $\begin{array}{l}\text { Capability } \\
\text { Opportunity }\end{array}$ \\
\hline & $0: 14$ & $1: 27$ & $\begin{array}{l}\text { How do I get my hearing aids } \\
\text { repaired? }\end{array}$ & & $\begin{array}{l}\text { Environmental context; } \\
\text { Social influences }\end{array}$ & Opportunity \\
\hline
\end{tabular}


Development of an mHealth intervention

\begin{tabular}{|c|c|c|c|c|c|c|}
\hline & $4: 40$ & $5: 29$ & $\begin{array}{l}\text { Where can I find help/support for } \\
\text { any hearing problems? }\end{array}$ & & Social influences & Opportunity \\
\hline \multirow{5}{*}{$\begin{array}{l}\text { Communication tactics } \\
\text { https://youtu.be/gssPxFtB0e8 }\end{array}$} & $1: 28$ & $2: 23$ & What tips can help me improve & \multirow{5}{*}{$\begin{array}{l}\text { Communication with } \\
\text { others }\end{array}$} & $\begin{array}{l}\text { Social influences; } \\
\text { Fnvironmental }\end{array}$ & Opportunity \\
\hline & $4: 54$ & $5: 24$ & & & & \\
\hline & $2: 38$ & $3: 54$ & $\begin{array}{c}\text { What can I change around me to } \\
\text { help improve conversations? }\end{array}$ & & Behavioural regulation & Capability \\
\hline & $3: 55$ & $4: 41$ & $\begin{array}{l}\text { What can I do to help me take } \\
\text { part in conversations in } \\
\text { restaurants, supermarkets and } \\
\text { cars? }\end{array}$ & & Environmental context & Opportunity \\
\hline & $5: 56$ & $6: 43$ & $\begin{array}{l}\text { How do I work with others to } \\
\text { help me take part in } \\
\text { conversations? }\end{array}$ & & Social influences & Opportunity \\
\hline \multirow{4}{*}{$\begin{array}{l}\text { Using the phone and other devices } \\
\text { https://youtu.be/NRzIoBL6Y4k }\end{array}$} & $0: 31$ & $2: 15$ & $\begin{array}{l}\text { How do I use the telephone with } \\
\text { my hearing aids? }\end{array}$ & \multirow{4}{*}{$\begin{array}{l}\text { Using phones and other } \\
\text { devices }\end{array}$} & $\begin{array}{l}\text { Knowledge; } \\
\text { Physical skills }\end{array}$ & Capability \\
\hline & $2: 16$ & $3: 31$ & $\begin{array}{l}\text { How do I use the loop system } \\
\text { with my hearing aids? }\end{array}$ & & Knowledge & Capability \\
\hline & $3: 32$ & $4: 36$ & $\begin{array}{l}\text { What other devices can I use with } \\
\text { my hearing aids? }\end{array}$ & & $\begin{array}{c}\text { Knowledge; } \\
\text { Environmental context }\end{array}$ & $\begin{array}{l}\text { Capability } \\
\text { Opportunity }\end{array}$ \\
\hline & $4: 47$ & $5: 11$ & $\begin{array}{l}\text { Who can I contact for more } \\
\text { information about other devices? }\end{array}$ & & Social influences & Opportunity \\
\hline
\end{tabular}


Supplemental Materials 3. Collated feedback generated by users during each development iteration.

Usability testing: iteration (1) $-30 / 11 / 2018$

Home screen (i.e. select you hearing aid type)

- Would be preferable to have the same hearing aid for both options (alternative suggestions: blur or only show outline of hearing aid)

\section{Name screen (i.e. enter you name)}

- When in 'private' or 'incognito' browsing mode, cannot continue after entering name. Can this issue be resolved?

\section{Four options (i.e. select sections you would like to explore further)}

- Preferable to have different pictures for each of the four options.

- Rather than a slider, users expected to tap on the picture to view the videos (like the home screen).

- All users would rather select one area, view the videos, and then go back to look at the other areas. As a result, the slider/'view your selections when ready' are not needed.

- They thought selecting multiple areas at once would be confusing/overwhelming for new hearing aid users/older adults.

○ Needs to be a 'back' option to return to hearing aid type - could this be positioned where the 'menu' and 'help' options currently are? If you select 'back' in web browser, it returns to home screen, irrespective of which screen you are viewing.

- The picture/circle could change colour when user has selected it, so they can keep track of what they have already selected.

- Remove 'Custom earmould' from sentence 'Custom earmould - Select sections that you would like to explore further'.

\section{Your videos screen}

- Change 'Welcome - You have selected information on Custom earmould hearing aids' to 'Welcome - You have selected information on how to use your hearing aids' [changes depending on option selected from previous screen]

O If this is possible, can then remove 'How to use my hearing aids' shown underneath welcome message.

- Some users didn't know that they needed to tap on the questions to expand and see the video.

$\circ$ Instead, would prefer to see a list of videos (between 6 and 10 maximum), with questions next to them.

○ The light green text on grey background was also difficult to read.

- All users disliked the slider option and didn't notice that tapping it moved the video into movie reel at the top of the screen.

- All users expected to tap on the video image/thumbnail and for it to play in a new window.

- Once tapped/played, would like the question to change colour, so can see that it has been viewed.

- Majority of users did not like the movie reel option at the top of the screen. 
- Some suggested it could be moved to the bottom, showing you what you have previously watched, although majority thought it was over-complicated and should be removed completely.

- Majority of users all said that they would have prefer to watch one video at a time, rather than watch a number of selected videos altogether.

- Majority of users didn't think that the video should be broken down into smaller segments (i.e. it was confusing, overwhelming, and unclear).

○ Commented that the original videos are around one-minute, so it is fine to go back and watch again. Also, the videos can be paused/rewind/fast-forward. Therefore, breaking them down might be unnecessary.

- When video opens in new pane, could the question that it's addressing appear at top instead of "Your selected video learning"?

- Also, one user thought it would be good to have a 'replay' option when the video finished - currently have to close and press again, which was frustrating.

- Needs to be a 'back' option to return to previous four options screen - could this be positioned where the 'menu' and 'help' options currently are? If you select 'back' in web browser, it returns to home screen, irrespective of which screen you are viewing.

- Can we re-word the following questions:

○ 'How do I put in my hearing aid correctly?' to 'How do I put my hearing aids in?'

○ 'How do I take-out my hearing aids correctly?' to 'How to I take my hearing aids out?'

\section{Interactivity}

- Majority of users were confused between number one and two on hearing aid image. Would it be possible to add arrows instead so it is clear they are referring to separate parts of the hearing aid?

- Currently, can only drag correct answer in box, otherwise bounces back to origin.

○ Would it be possible for separate feedback (correct/incorrect) to pop-up for each response?

○ Would prefer that the feedback is given for each response as you go along, rather than pop-up at the end.

- Also, need to [remove square bracketed text], these denote DM's comments/notes and should not be shown to the user.

- Preferable for the interactivity to open in a pop-up window pane, like the videos, rather than a new web-browser tab, as the majority of users did not know how to go back to the videos.

- Should include 'close' button at the bottom.

- If select interactivity, could video pane close automatically? Otherwise, there are two screens to close in succession, which could be confusing

Usability testing: iteration (2) - 11/01/2019

\section{Home screen (i.e. select you hearing aid type)}

- Would be preferable to have the same hearing aid for both options. NB. I have the hearing aids on my desk for you to photograph, I just need to get them to you!!

- Need to revise 'Menu' options:

○ 'Choose your learning path' is redundant here and the advice might confuse some people. 
- Menu option 'About us' and 'Contact' needs inserting.

- Menu option 'Select you hearing aid' takes you to four areas to explore further, which is confusing.

- Twitter, Facebook, YouTube, etc. located at the bottom of the page seem inappropriate and a distraction. These should be removed.

\section{Name screen (i.e. enter you name)}

- When in 'private' or 'incognito' browsing mode, cannot continue after entering name. Can this issue be resolved?

\section{Four options (i.e. select sections you would like to explore further)}

- Make 'Welcome' text larger - same font size as 'select the sections you would like to explore further'.

- Unable to navigate back to home screen (i.e. select your hearing aid type). The only option is to us back button in web browser. In the next window (i.e. your videos), a 'return to selection' button has been added in the top right. I would advise that this button is removed and replaced with a 'Back' button positioned in the bottom right of the screen (this would be consistent with the 'Close' button in the pop-out video screen). The 'back' button should be displayed on all windows where appropriate. Perhaps we should also include a navigation option in the menu?

$\circ$ Also if you return to the 'select your hearing aid type' the videos in 'your previous sections' in the 'your videos' screen all disappear. Can this be fixed?

- When you make a selection, would it be possible to change the colour of the text rather than fade the image? Fading might suggest that the content is no longer available to the user?

- Preferable to have different pictures for each of the four options.

- Delete word 'further' and change 'sections' to 'section' from sentence, 'Select the sections that you would like to explore ther?'. Also, remove question mark and replace with full-stop, as this not grammatically correct.

- Switch '3. Communication with others' and '4. How to look after my hearing aids' (i.e. 3. How to look after my hearing aids; 4 . Communication with others).

\section{Your videos screen}

- Remove 'Welcome', so only displays user's name. Also, need to make the text larger (see above comment regarding possible font size).

- When you select a video, would it be possible to change the colour of the text rather than fade the image? Fading might suggest that the content is no longer available to the user?

- Change 'your previous sections' to 'videos you have viewed' or 'viewed videos'? The latter is perhaps more informative than the former.

- Would it be possible to play a video by selecting the image in the 'your previous selections'?

- Video thumbnails should all be changed so that only one image is displayed, rather than multiple, over-lapping images.

- Not all questions have question marks, please add. Also, double-check the wording/order of questions in attached document, as these have now all been amended.

- 'Why does it take time to get used to wearing my hearing aids' video does not play. 
- Can the colour of the 'replay video' button in the video pop-out screen be changed, as it is too similar to the background colour and the contrast is poor?

\section{Interactivity}

- Majority of users were confused between number one and two on hearing aid image. Would it be possible to add arrows instead so it is clear they are referring to separate parts of the hearing aid?

- Currently, can only drag correct answer in box, otherwise bounces back to origin.

○ Would it be possible for separate feedback (correct/incorrect) to pop-up for each response?

- Would prefer that the feedback is given for each response as you go along, rather than pop-up at the end.

- Also, need to [remove square bracketed text], these denote my comments/notes and should not be shown to the user.

Usability testing: iteration (3) - 30/01/2019

\section{Home screen (i.e. select you hearing aid type)}

- Would be preferable to have the same hearing aid for both options.

- Need to switch custom and open fit options.

- Need to revise 'Menu' options:

- Content for 'About' and 'Contact' needs inserting.

- Discussed that the 'About' should be added as a drop-down under the text 'Welcome to m2Hear', informing users about the project and/or how to use the platform (MF and DM to provide relevant text).

- Add a Survey Monkey link to Menu for users to provide feedback, similar to that available for $\mathrm{C} 2 \mathrm{Hear}$ Online?

\section{Name screen (i.e. enter you name)}

- When in 'private' or 'incognito' browsing mode, cannot continue after entering name. Can this issue be resolved?

\section{Four options (i.e. select sections you would like to explore further)}

- The audio quality for some of videos is very poor when played via loudspeaker (but not via headphones). A similar issue was experienced when videos uploaded to YouTube. Please check this for ALL mRLOs.

- No longer says 'Welcome' followed by users name. Is it possible to add 'Welcome' on this page only?

- Back button added to bottom right of page. Should also be added to top right. Is it possible to enable the web browser back button to navigate through the platform also, as this was many users' preference?

- When you make a selection, would it be possible to change the colour of the text rather than fade the image? Fading might suggest that the content is no longer available to the user?

- Need to amend four areas to five (see also attached Word document).

$\circ$ Using your hearing aids

- Getting used to your hearing aids

- Looking after your hearing aids

- Communication with others 
- Using the phone and other devices

- Remove images, and place text within circles instead.

\section{Your videos screen}

- Can font size be consistent for ALL text? Currently the highlighted text (in yellow/light blue) is smaller.

- Align questions text to centre of mRLO thumbnail (as opposed to top).

- Please see attached Word document for amended sub-headings (highlighted in light blue) and video questions. Also note, the order of questions has changed and they are no longer numbered. DM would be more than happy to help with this.

- When you select a video, would it be possible to change the colour of the text rather than fade the image? Fading might suggest that the content is no longer available to the user?

- Would it be possible to play a video by selecting the image in the 'Viewed videos'?

- Currently, the 'viewed videos' lists all the videos watched in order. Would it be possible to remove duplicates (i.e. when a video is viewed more than once), keeping it in the list where it was most recently viewed?

- Also, if you watch more videos than the size of the grey bar, they go outside of it (i.e. no scroll option).

\section{Interactivities}

- Majority of users were confused between number one and two on hearing aid image. Would it be possible to add arrows instead so it is clear they are referring to separate parts of the hearing aid?

- Would it be possible for separate feedback (correct/incorrect) to pop-up for each response?

○ Would prefer that the feedback is given for each response as you go along, rather than pop-up at the end.

$\circ$ Also, need to [remove square bracketed text], these denote my comments/notes and should not be shown to the user.

- Please see attached Word document with quiz questions and/or interactivities that should be associated with the corresponding mRLO. Typing errors from the quiz questions that are currently online have been highlighted.

Usability testing: iteration (4) - 19/02/2019

\section{Usability/feedback on m2Hear platform}

"I have been working through the app and have found it very useful, I especially like that you can dip in and out of it, and return to the sections that are relevant to you, at times to suit you".

"I wanted to look for what I needed to know, and could find it. If I first got HAs, I would go through all of it. But as I've had hearing aids for a while, I was looking for 'other' information (e.g. how to use phone was good, and what other devices are around).

\section{Home screen (i.e. select you hearing aid type)}

a. General impression 
- Good, simple, obvious what to do.

- Liked language, inviting and friendly.

- Colours were very relaxed and restful.

- Show two different HA, doesn't show my HA, but shows the mould - I know exactly which one I want.

b. Images suitable?

- Images are great, clear that referring to fitting type rather than hearing aids.

- Smaller font size acceptable. prefer not to be too big.

c. What should/shouldn't we include in 'About this project'?

- Should be timeless and not too long.

- Suggested we use lay summary from original grant application?

- Limit to 150-200 words?

\section{Name screen (i.e. enter you name)}

a. General impression

- All felt acceptable, no additional comments to add.

- Doesn't save name, had to enter each time, but wasn't a problem 'didn't bother me'.

\section{Five options (i.e. select sections you would like to explore further)}

a. General impression

- Five areas were acceptable and liked that there were ordered in terms of the patients 'chronological' journey.

- Colour contrast ok, white on blue.

- Font sizes of text too small on tablet, portrait circles overlap - text not legible (PC and iPhone OK)

- Wording In the bubbles should be bigger.

- Circles could be made bigger and maybe order in a circle/clock face/grid, rather than all on one line - currently there is a lot of wasted blue space beneath the circles, why is this?

- Plenty of room on screen to put bubbles in bottom half.

b. Wording of titles ok?

- No. More concise titles (provided) have not been used. PPI felt these were much better than existing as clearer and requires less effort

c. Should we have more areas (6-8) so fewer videos in each?

- No, this is just fine.

\section{Your videos screen}

a. Quiz and options?

- Helpful and liked them.

- Quiz - this can only be used once. If the user wants to see the other options they have to go in again - a button is required 'return to quiz?' as is the case with $\mathrm{C} 2 \mathrm{Hear}$ and $\mathrm{m} 2 \mathrm{Hear}$ activities (i.e. replay activity).

- Quizzes - would like to go back, once you're wrong, you're wrong, and it doesn't allow you to go back and try again.

- The open fit has the quiz for the custom mould not the open fit, which doesn't make sense.

b. No., of videos in each area? 
- No concerns regarding number of videos. Happy to scroll and what was expected.

c. Interactivities?

- Information very good. Happy with all topics/content, and questions.

- All interactivities - if text/images appear in bottom, outside of view within the pop-up window, you can't scroll down to see them on iPad as no scroll bar appears (but does if looking on a PC).

- In custom activity "how to clean your hearing aid" currently only one image, there should be 5. The single image won't drop after dragging.

- Label HA Activity - there is one activity repeated 4 times. PPI didn't like this as it looked like something was wrong. Suggested only have two mRLOs with this activity - suggested "hearing aid left/right" and changes programmes".

- How to clean HA - images are too small and the description should be alongside the image without having to hover as this doesn't happen with tablet use. It is vital that the description is seen as this provides the context, images are meaningless on their own - alternative images would not help

- Restaurant activity - doesn't work on tablet or smartphone. I can't select Table and doesn't the display feedback on tablet. On PC, only the bar works, other selections don't display - it looks like they are to click on is not aligned with the table. This activity was very well-reviewed in usability testing, and is an impt activity.

\section{General comments}

a. Thoughts on 'Back' button

- Would prefer to be able to use web browser back button to navigate through screens. 'Why can't we use the web browser back button?'

- Would like to keep integrated 'back' button, but should be in top left on ALL pages. Currently, it lacks consistency.

- Prefer to use back button on platform, rather than web browser. 'Back' navigation doesn't work properly; if 'Back' button is used at top takes you back to Welcome page. 'Back' button at bottom works perfectly.

b. Anything you would change to make it better?

- Number of grammatical/typographical errors throughout RLO subtitles.

- Video screen - the RLO play line overlaps with subtitles and don't always disappear. 